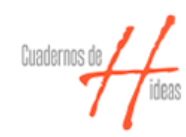

Cuadernos de $\mathrm{H}$ ideas

ISSN: 2313-9048

cuadernosdehideas@perio.unlp.edu.ar

Universidad Nacional de La Plata

Argentina

\title{
La reforma laboral española según los diarios argentinos
}

Coscia, Vanesa; Russo, Raffaele

La reforma laboral española según los diarios argentinos

Cuadernos de H ideas, vol. 13, núm. 13, 2019

Universidad Nacional de La Plata, Argentina

DOI: https://doi.org/10.24215/23139048e027

Esta obra está bajo una Licencia Creative Commons Atribución-NoComercial-Compartirlgual 4.0 Internacional 
Artículos

\section{La reforma laboral española según los diarios argentinos}

The Spanish labor reform by the Argentinean press

Vanesa Coscia

DOI: https://doi.org/10.24215/23139048e027

Instituto de Investigaciones Gino Germani-Universidad de

Buenos Aires/conicet, Argentina

vanesa.coscia@gmail.com

iD http://orcid.org/0000-0003-1517-2705

Recepción: 12 Junio 2019

Aprobación: 27 Noviembre 2019

Raffaele Russo

Publicación: 21 Diciembre 2019

Facultad de Física "Ettore Pancini", Universidad Federico

II, Napoli, Italia

raffael.russo@gmail.com

(iD http://orcid.org/0000-0003-4857-6626

Recepción: 12 Junio 2019

Aprobación: 27 Noviembre 2019

Publicación: 21 Diciembre 2019

\section{Resumen:}

En este artículo se analiza cómo los principales diarios de Argentina (Clarín y La Nación) representaron la reforma laboral española de 2012 y, en particular, las nociones de flexibilización y precarización laboral. En el contexto global actual, donde se han sancionado recientemente reformas laborales o se debaten nuevos cambios: Italia y Francia en Europa; México, Brasil y Argentina en América Latina, resulta interesante analizar, a la luz del caso español, cuáles son los énfasis noticiosos y sentidos privilegiados por los grandes medios, respecto del trabajo, los sindicatos y los derechos laborales.

PALABRAS CLAVE: reforma laboral española, flexibilización, medios masivos, representaciones globales.

\section{ABstract:}

The aim of this article is to analyze how the main Argentine newspapers (Clarín and La Nación) represented the Spanish labor reform of 2012 and, in particular, the concepts of labor flexibilization and precarization. In the current global context, where labor reforms have recently been sanctioned or new changes are being debated: Italy and France in Europe; Mexico, Brazil and Argentina in Latin America, it is interesting to analyze, in the light of the Spanish case, which are the privileged emphases and privileged meanings by the mass media, about labor, unions and labor rights.

KEYWORDS: Spanish labor reform, flexibilization, mass media, global representations.

\section{INTRODUCCIÓN}

Este estudio tiene como objetivo identificar y analizar qué aspectos se destacaron y cuáles se desestimaron desde los principales diarios argentinos en sus versiones digitales: Clarín/clarín.com y La Nación/ lanacion.com.ar sobre la cobertura de la reforma laboral española de 2012.

Luego de la crisis internacional del 2008, en varios países de Europa y en el marco de una reestructuración global del capitalismo financiero, se implementaron reformas y modificaciones en las legislaciones laborales de diversas naciones, con el objetivo de hacer frente a los problemas del mercado de trabajo y a la crisis laboral.

La reforma laboral española del 2012, sancionada a través del Real Decreto-ley 3/2012 del 10 de febrero por el gobierno de Mariano Rajoy, del Partido Popular, se enmarca en dicho movimiento y tuvo diversas particularidades, entre las que se pueden destacar: la facilitación de los despidos por causas económicas, la rebaja de las indemnizaciones, el privilegio de los contratos por empresas por sobre los convenios colectivos 
nacionales y el desplazamiento del sindicato como participante en las negociaciones por indemnización, entre otras cuestiones. Con una línea similar, la sanción de reformas laborales en Italia introdujo también cambios que flexibilizaron aún más las condiciones laborales. En el contexto latinoamericano actual, en el que también se sancionaron, recientemente, reformas laborales como es el caso de México (en 2012) y de Brasil (en 2017).

Si bien las reformas laborales de sesgo neoliberal tienen su origen en los años '80, junto al avance de los gobiernos de Margaret Thatcher en Inglaterra y de Ronald Reagan en Estados Unidos, su espíritu se actualiza "desde los nuevos proveedores de ideología conservadora, los thinktanks patronales y -en algunos casosacadémicos, que desde hace tiempo vienen sentando las bases ideológicas y metodológicas de una involución neoliberal, a la espera de una oportunidad que la actual crisis económica y orientación política hacen posible" (Beneyto, 2012: 5).

Entendiendo a la cultura como un campo de disputa por los significados sociales (Hall, 1981) y al escenario mediático como uno de los espacios públicos donde se libra una lucha por quién define lo legítimo y lo que no lo es, en cada momento histórico, proponemos analizar de qué modo fue representada la reforma laboral española por parte de los diarios argentinos más vendidos a nivel nacional: Clarín/clarín.com y La Nación/ Lancion.com.ar. Consideramos que la relevancia de este estudio radica en que, en el contexto latinoamericano actual, en el que se sancionaron recientemente reformas laborales, como es el caso de México y Brasil, o en el que se comienzan a debatir públicamente las posibilidades de implementar una en Argentina, resulta interesante identificar énfasis y tendencias globales en las representaciones mediáticas en momentos de crisis y de reestructuración de las relaciones laborales. Esto nos permitirá develar elementos comparables o análogos entre los países, en relación con la construcción de consensos sociales sobre las atribuciones que adquiere el trabajo, los sindicatos, los derechos laborales en las sociedades actuales.

Para estructurar este artículo, se define en primer lugar qué se entiende aquí por flexibilización y por precarización laboral, a partir de la revisión y el análisis de la literatura especializada en estudios laborales; en base a ello se construyen una serie de categorías analíticas que permiten tipificar estos procesos y analizar aquello que los medios argentinos destacan sobre la temática. Luego se seleccionan un conjunto de noticias que comprende los tres meses anteriores a la sanción de la reforma laboral española, el mes de su sanción y los tres meses posteriores, es decir, un período que abarca desde noviembre de 2011 hasta mayo de 2012 inclusive, y se identifican de qué modo fueron virando o reproduciéndose ciertos destacados y lecturas sobre la reforma laboral. Finalmente se articulan las categorías provenientes de los estudios laborales con aquello que los medios visibilizan, resaltan o jerarquizan en sus coberturas, focalizando en los sentidos sociales privilegiados que recorren a las nociones de flexibilización y precarización laboral. Este abordaje, de tipo cualitativo, se complementa con la utilización de las herramientas de software para la configuración, cuantificación y análisis de datos, denominada Data Modeling y Data Warehouse provenientes del campo informático, con el objetivo de sistematizar las informaciones provenientes de los medios.

\section{Definiciones ConCEPTUALES}

\subsection{Flexibilización y precarización laboral}

En este estudio, tanto la flexibilización como la precarización son consideradas procesos sociales que representan "la cara más visible de los efectos de la reestructuración económica en el mercado laboral" (Bonofiglio y Fernández, 2003: 4). ${ }^{1}$ Para la aproximación a estas categorías, interesa hacer una premisa: nos referimos a la flexibilización del mercado de trabajo y a la precarización de las condiciones de vida de los trabajadores, como dos conceptos que se articulan y que, de algún modo, van en línea con aquello planteado por De Vito cuando ubica la flexibilización del lado del sistema y del poder de gestión, dado que "expresa la voluntad de los sectores empresarios o patronales de controlar y sincronizar la mano de obra, según sus 
necesidades políticas y productivas" (De Vito, 2018: 124). Y, a su vez, la noción de precarización se la atribuye a una condición de los trabajadores. En palabras de Gallino (2014), se podría expresar como la flexibilización del trabajo, por un lado y la precarización de la existencia, por el otro. En el marco de las dicotomías precarioestable, atípico-estándard, cierto-incierto, que destaca Basile, "en la precarización, se fragmenta y se debilita a los trabajadores, al tiempo que se le niega garantías y derechos laborales (Basile, 2009: 157). Se asiste así a lo que Bourdieu (1998) llama disposiciones precarizadas, producidas por la inseguridad en el empleo.

Por otro lado, dentro del concepto de flexibilización, según los estudiosos del campo laboral, existen subcategorías: "en entrada", "en salida", "salarial" e "interna". A tal respecto, precisamos que la flexibilización "en salida" supone la facilitación de los despidos, a partir de bajar los montos de las indemnizaciones o de eliminar trabas para despedir trabajadores; aquella "salarial" supone la capacidad del empresario de modificar el nivel de los salarios según la evolución de la economía y su propia tasa de ganancia (De La Garza Toledo, 2000a); la flexibilidad "en entrada" supone facilidades que otorga la legislación a los empresarios para contratar trabajadores, a través de la posibilidad de realizar contrataciones temporarias directas e indirectas, obtener beneficios fiscales, blanqueos, reembolsos, etc. Finalmente, la flexibilidad "interna” supone el concepto de polivalencia, es decir, la intercambiabilidad de tareas y de sectores, a la vez que implica la posibilidad de aumentar el producto por trabajador, a partir de la eliminación de barreras que permitan al empresario determinar la extensión e intensidad de la jornada laboral (De la Garza Toledo, 2000b).

Por su parte, para la categoría de precarización no parecen mencionarse, desde los estudios laborales, subdivisiones específicas. En este caso, sólo con fines analíticos y en base a aquello que se publica en los medios, se crean tres sub-categorías que se aplican a la noción de precarización: "contractual", "de derechos" y "global". En las tres, el foco está puesto en la sustracción o carencia de protecciones y seguridades de distinto tipo para el trabajador, es decir, implica la disminución de obligaciones por parte de los empresarios y la retirada del Estado en la prestación de servicios complementarios como aportes jubilatorios o derechos de salud (Lindenboim, Serino \& González, 2000). En este estudio, y articulando esta definición general con aquello que se puede identificar en las noticias, la primera de las tres sub-categorías "contractual" se refiere a la tipología de contratos y comprende desde la referencia a contratos atípicos, inestables, tercerizados, temporales hasta modificaciones en los convenios colectivos de trabajo. La segunda sub-categoría, "de derechos", se define como aquella a partir de la cual se hace referencia en las noticias a la mención específica de la transformación, ausencia o quita de derechos laborales con la introducción de las reformas: sin derechos a aportes jubilatorios, a coberturas de salud, a vacaciones pagas, a períodos de licencias, etc. La última, denominada "global", supone la puesta en serie en la superficie mediática del caso español con la precarización en otros países de la zona Euro, en el mismo período.

\subsection{Medios masivos y representaciones}

En el presente estudio, como se adelantó previamente, consideramos conceptualmente a la cultura y a los medios masivos de comunicación desde la mirada de Hall (1981), que entiende a la cultura como un campo de disputa por los significados sociales. En ese sentido, es posible pensar la superficie mediática como un espacio de confrontaciones y diálogos donde se va definiendo lo legítimo y lo que no lo es. Estas disputas se pueden enmarcar en aquello que Angenot (2012), desde la impronta de Gramsci (1974), denominó begemonia de lo decible y de lo pensable, es decir, lo que es posible y se habilita a pensar y a decir en cada coyuntura. En este marco, los medios masivos, lejos de concebirse como plataformas neutrales, deberían pensarse como corporaciones de poder concentrado, con discursos reguladores y normalizadores que inciden en la configuración de subjetividades y de imaginarios sociales (Bernstein, 1998) y que no pueden concebirse por fuera de las relaciones de poder y del lugar que ocupan en la estructura del mundo globalizado y de cada realidad nacional. ${ }^{2}$ 
Por tal motivo, para analizar cómo los discursos mediáticos se articulan de modo complejo en cada coyuntura histórica, es importante tener en cuenta la permeabilidad de los medios masivos, es decir, la articulación de estos discursos con los elementos históricos y sociales de una coyuntura determinada. Esto supone que el contexto en el cual se producen ciertos discursos de los medios dota de un marco de significación histórica a tales discursos. Se abandona así la idea de inmanencia del discurso, es decir, no se puede pensar el discurso social ni por fuera del contexto en el cual se produjo y se puso en circulación, ni por fuera de su articulación con otros discursos.

En esta línea, las representaciones mediáticas, concebidas como conjuntos de discursos sociales e históricos, que son atravesados por operaciones de selección, apropiación y síntesis, se anclan en estructuras de sentidos sobre los imaginarios sociales (Rodríguez, 2014). Tales representaciones iluminan una determinada versión de la realidad, entre otras tantas posibles, y permiten visibilizar ciertos aspectos -y opacar otros- sobre una temática. Todo lo cual deriva en la producción de lecturas preferenciales(Hall, 1981) que intentan direccionar la mirada sobre las problemáticas sociales, en cada momento histórico.

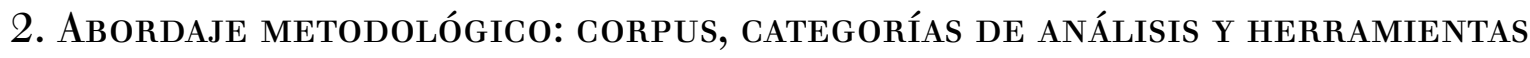

Para el análisis de la cobertura mediática de la reforma laboral española, sancionada en febrero de 2012, por parte del entonces presidente Mariano Rajoy del Partido Popular, ${ }^{3}$ se rastrearon de qué modo se pusieron en juego las categorías y subcategorías de flexibilización y de precarización en la superficie mediática, a partir de los elementos de construcción de las noticias (ubicación en secciones, etiquetas, enmarcados, títulos, adjetivaciones, fotografías, epígrafes, series discursivas, etc.), en los dos portales web de los principales diarios argentinos Clarin y La Nación. ${ }^{4}$

Esto implicó una aproximación metodológica fundamentalmente de tipo cualitativo, en la cual se focalizó en las disputas por los sentidos sociales que adquieren ciertas nociones claves (Hall, 1981) como flexibilización o precarización laboral, en el escenario mediático, en la coyuntura analizada. Tal enfoque se combinó con el uso de herramientas provenientes del campo informático, como son data-modeling y datawarehouse, que posibilitó, además, cuantificar algunas informaciones, diseñar gráficos de tendencias y de evoluciones relacionadas con la visibilidad dada a la temática.

Para la construcción del corpus se realizó una revisión general de las noticias sobre la reforma laboral española, a través de palabras claves como "reforma laboral española", "reforma española" en los archivos digitales de los portales web de los diarios seleccionados, entre noviembre de 2011 y mayo de 2012. Se relevaron un total de 50 noticias que abordaron específicamente el tema de la reforma laboral española. ${ }^{5}$ Para modelizar y ordenar las informaciones de estas noticias se utilizó la herramienta del data-modelling y se colocaron estas noticias ( 35 de La Nación y 15 de Clarín) en una planilla, tabla o fact table en las que, previamente, se habían organizado diversas dimensiones de análisis tales como "medio", "secciones", "tipo de noticias", tags o "etiquetas", etc. que se fueron poniendo en relación con cada una de las 50 notas. Esto permitió, para dar un ejemplo, relacionar la entidad "medio" con aquella de "secciones" y conocer así en qué secciones de cuáles medios se publicaron la mayor cantidad de noticias sobre la reforma laboral española. $\mathrm{O}$ la entidad "medio" con los "tipos de notas" para conocer si se utilizó más la crónica o la nota de opinión a la hora de cubrir este tema. Todas estas entidades se colocaron en la fact table, se les asignó un valor y luego se analizaron las relaciones posibles entre los datos.

Para tener un panorama general de todas las relaciones posibles que pueden establecerse entre las categorías construidas, se coloca la planilla o fact table de las 50 notas y a su alrededor las distintas dimension tables o dimensiones de análisis (medio, secciones, tags, adjetivaciones, temas, etc.), diseñando un star schema o diagrama de tipo estrella: 


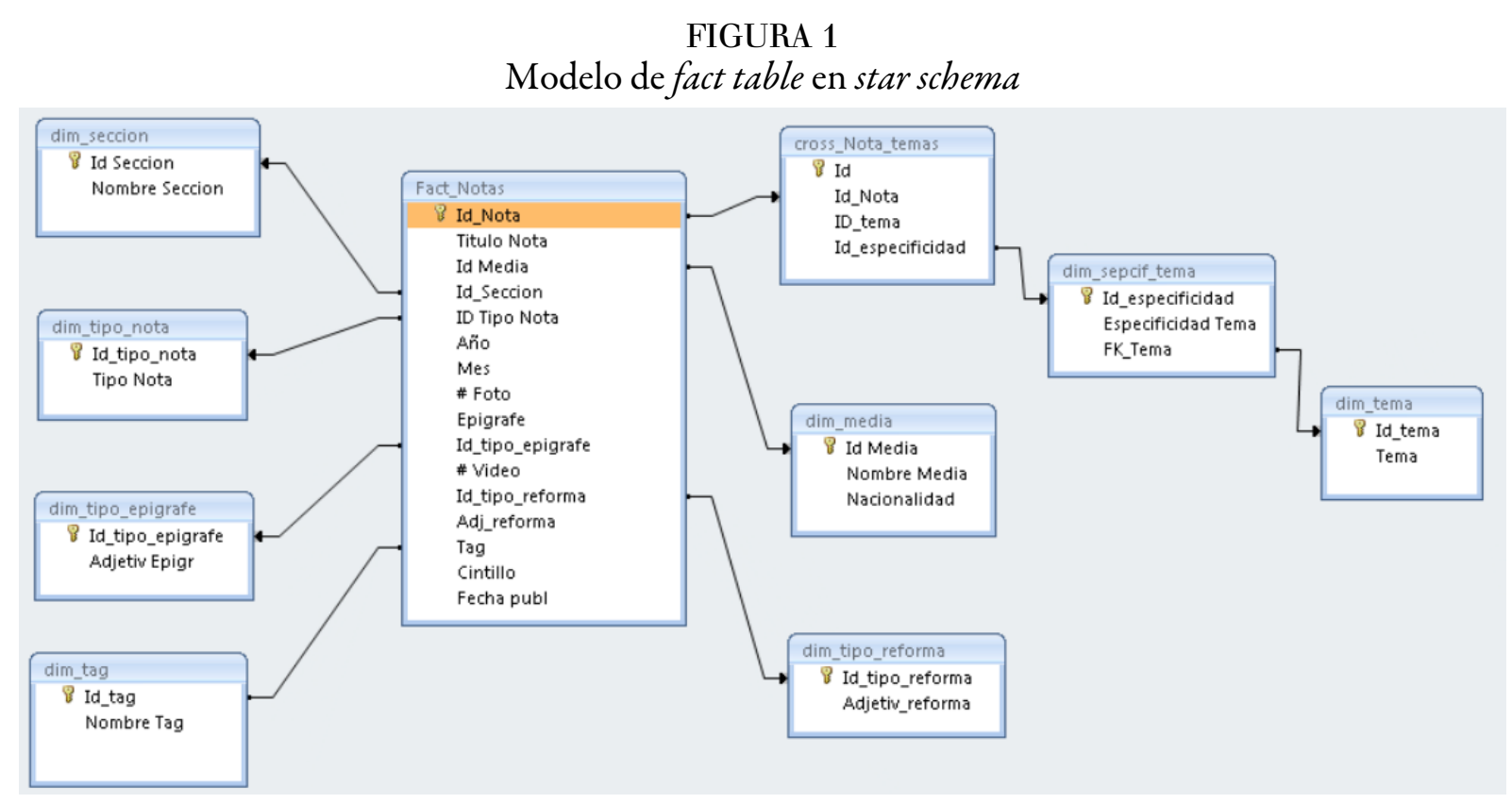

(Fuente: elaboración propia)

Para complejizar aún más el análisis, la fact table se puso en relación con otras dos dimensiones analíticas y jerárquicas: las entidades "temáticas" y las sub-entidades denominadas "especificidades de los temas", con el objetivo de entrecruzar los campos analíticos y conocer, por ejemplo, cuál fue el foco de atención puesto acerca de la flexibilización en las coberturas mediáticas y cuáles fueron los actores y voces privilegiadas en las noticias publicadas sobre tal cuestión.

Como se señaló previamente, las dos categorías de análisis o entidades temáticas "madres" en este estudio fueron Flexibilización y Precarización con sus diversas sub-categorías o sub-entidades temáticas. A tales categorías, se añadió otra denominada Actores o fuentes privilegias en las noticias. Cada entidad temática se desagregó del siguiente modo:

- Flexibilización: a) en salida; b) salarial; c) en entrada e d) interna;

- Precarización: a) contractual, b) de derechos y c) global;

- Actores: a) Organismos internacionales de crédito; b) empresarios y c) sindicatos.

Una vez construida la modelización de los datos (data-modeling), nos encontramos ante un pequeño modelo de depósito de datos (datamart). ${ }^{6}$ A cada una de estas entidades y sub-entidades, se les asignó un valor y se las puso en relación con la fact table para realizar un análisis cruzado de los datos, a partir del cual poder extraer las tendencias de los temas y subtemas más publicados y de los actores mayormente consultados por cada medio.

\section{3. ÉNFASIS, SENTIDOS Y TENDENCIAS EN LA REPRESENTACIÓN MEDIÁTICA}

En primer lugar, tal como se dijo previamente, se debe destacar que La Nación le dedicó más del doble de noticias (35) que Clarín (15) a la temática de la reforma laboral española en su superficie mediática. Además, por tratarse de un tema internacional para los diarios argentinos, la mayoría de las noticias fueron colocadas en las secciones dedicadas a la cobertura de exteriores denominadas "Mundo/El Mundo" (44 sobre 50) de los respectivos matutinos y sólo en unos pocos casos en la sección "Economía" ( 6 sobre 50), reforzando la variable económica de la crisis y del desempleo en la cuestión. 
Respecto de los tags o etiquetas, hemos observado que en ambos medios se destaca la noción de crisis para enmarcar las noticias que tematizan la reforma laboral española, como se ilustra en el siguiente gráfico, distinguiéndola según las diferentes escalas espaciales: más local “crisis en España” (4 sobre 50), más continental "crisis europea" (24 sobre 50) y más global "crisis económica global” (11/50), reforzando en este último caso la variable económica.

FIGURA 2

Gráfico del tag "crisis"

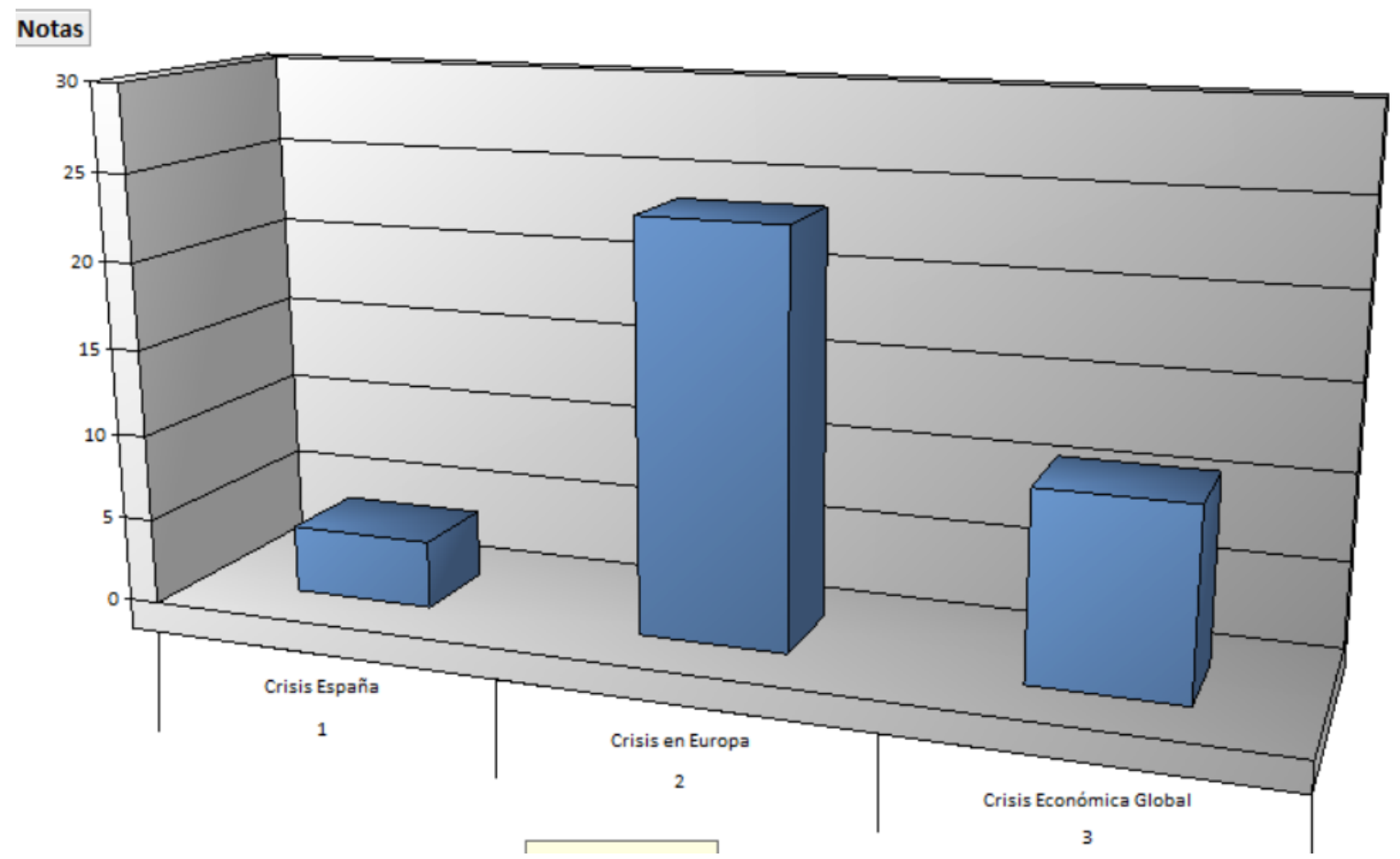

(Fuente: Elaboración propia)

De este modo, los tags privilegiados no son tanto, como podría esperarse, "la reforma laboral"/"conflictos gremiales" o incluso "empleo/desempleo", sino que se enfatiza la noción de crisis, haciendo referencia a la delicada situación que atraviesa España, en la cual se enmarca tal modificación. ${ }^{7}$ Relacionado con esta última cuestión, se han analizado también, los modos de adjetivar esta reforma, es decir, si se le asignaba una atribución negativa o positiva a la temática, desde los titulares, destacados y epígrafes de foto. En la mayoría de los casos analizados, no existe una adjetivación directa vinculada a la reforma, pero en los pocos casos en que se presenta una atribución es negativa y suele asumir un carácter dramático: injusta e ineficaz, panorama sombrío, una reforma que provoca descontento, desamparo, preocupación y hasta furia. Por lo tanto, sea desde los tags como desde los adjetivos utilizados, se puede identificar en los medios argentinos, una línea de dramatización y de espectacularización de este tipo de noticias, que privilegia lo emotivo por sobre lo informativo (Imbert, 2002), incluso desde las fotografías que los medios eligen incluir con sus respectivos epígrafes: "La calle. Un desempleado y sin techo español duerme bajo un puente en pamplona. El nivel de desocupación en España afecta a más de 5 millones” (España aplica más ajustes y congela el salario mínimo. 29/12/2011, Clarín) y "Desamparado. Dos hombres duermen en un cajero en Barcelona, una ciudad atravesada por la crisis" (Rajoy advierte que la economía y la desocupación española empeorarán, Clarín. 16/02/2012, Clarín): 


\section{FIGURA 3}

"La calle. Un desempleado y sin techo español duerme bajo un puente en pamplona. El nivel de desocupación en España afecta a más de 5 millones”

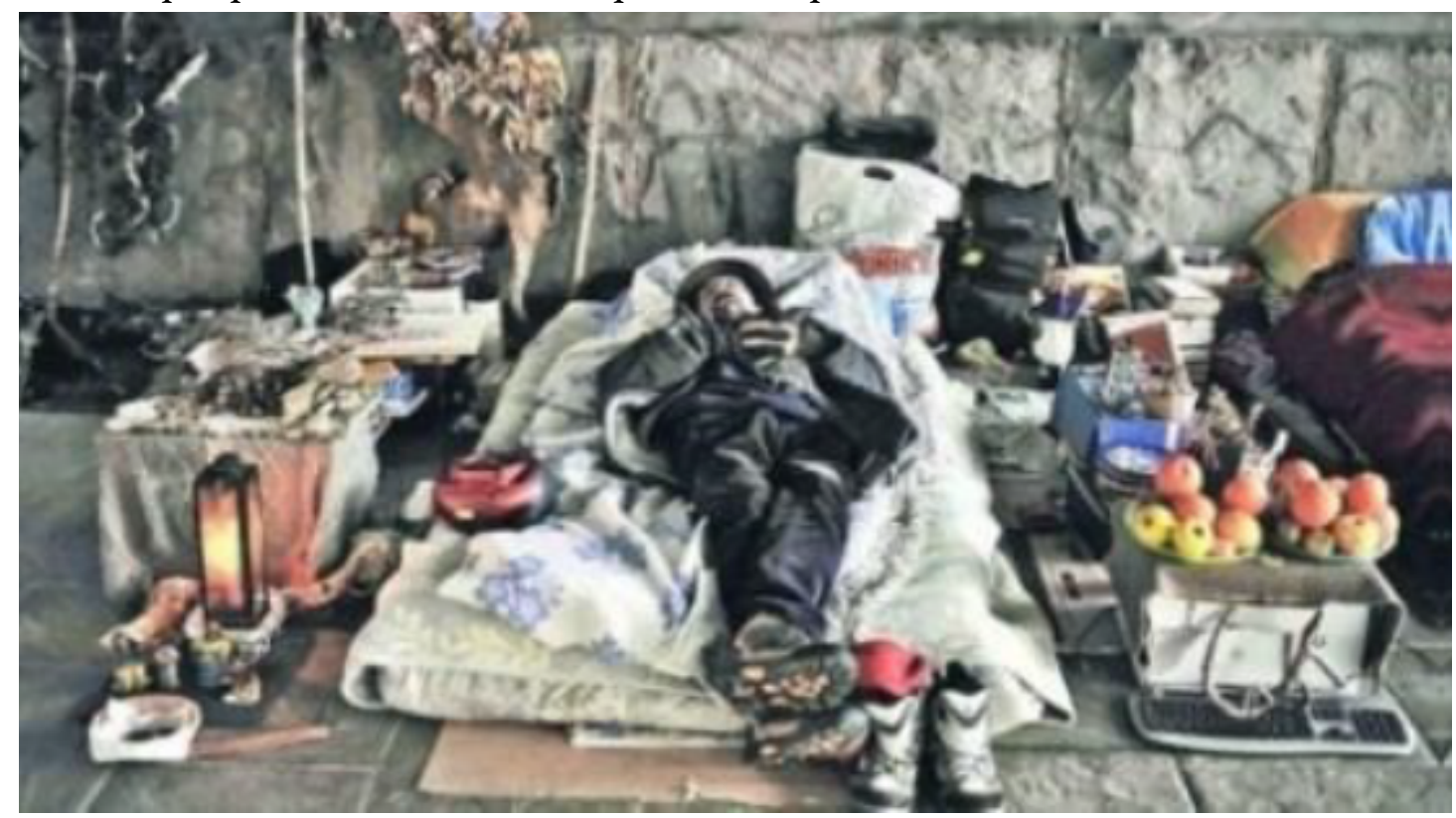

(España aplica más ajustes y congela el salario mínimo. 29/12/2011, Clarín)

FIGURA 4

"Desamparado. Dos hombres duermen en un cajero en Barcelona, una ciudad atravesada por la crisis"

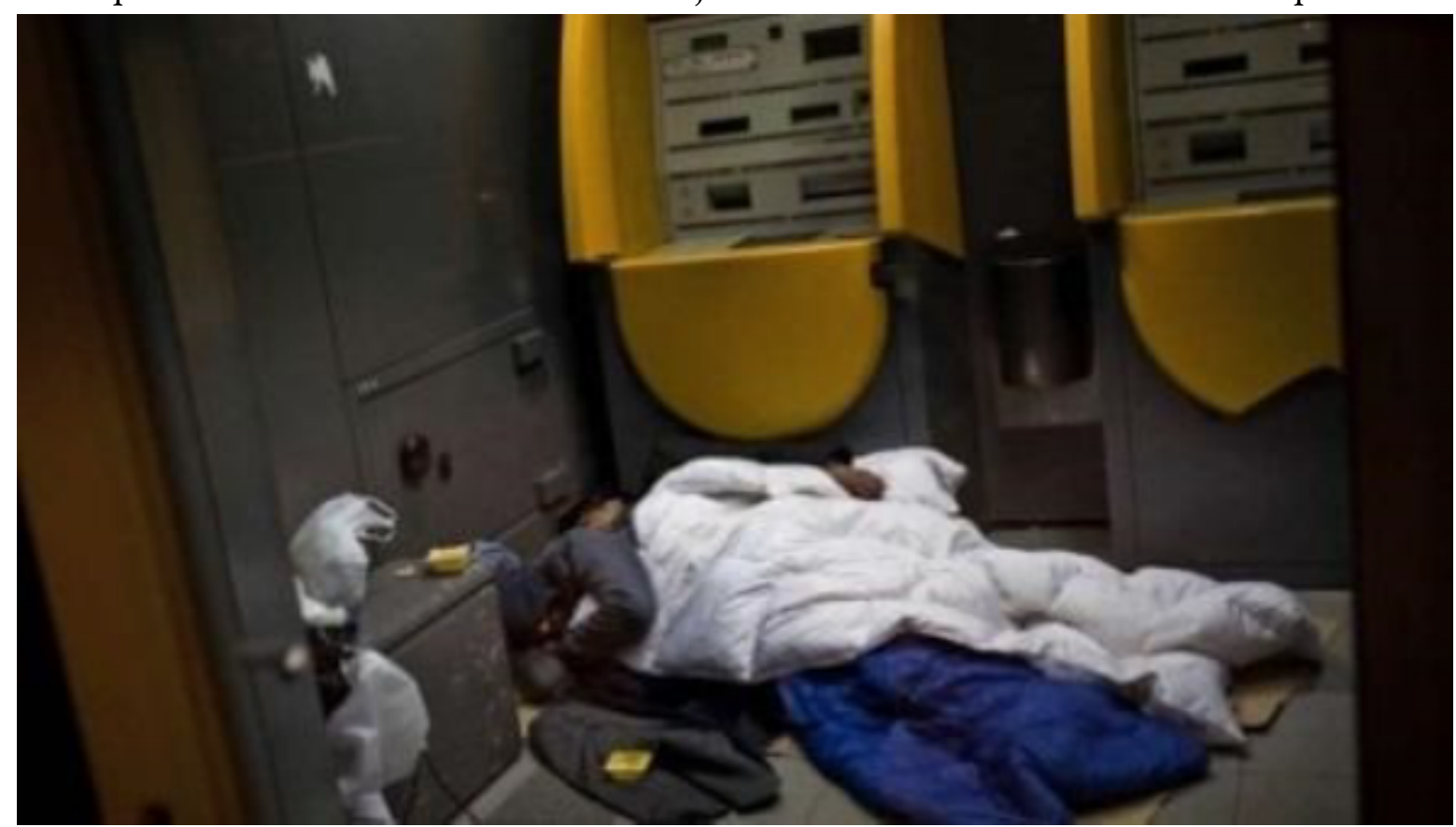

(Rajoy advierte que la economía y la desocupación española empeorarán, Clarín. 16/02/2012, Clarín)

Como menciona Ford (1994), la fotografía es uno de los lugares privilegiados de atención, luego de la tapa del diario y los titulares. Provoca, además, el efecto de "realidad", aumentando la verosimilitud de aquello que se informa. La imagen fotográfica resulta, a partir de esta propiedad y por su poder de persuasión, un instrumento útil para parecer "reflejo" y no construcción del acontecimiento. De este modo, se ocultan 
las huellas de una construcción en la fotografía (Sontag, 2004). En esta línea, a partir de la selección de imágenes y sus epígrafes, que señalan al lector el modo de leer esas fotos, se enfatiza y otorga alto grado de dramatismo a la situación social española. Se trata de aquello que Barthes (1962) denominó "recurso del dramatizado", intentando, en este caso a través de la fotografia de prensa, volver las noticias más impactantes a sus lectores. Así, tales imágenes sugieren, sin decirlo explícitamente que la reforma laboral es "urgente y necesaria", haciéndose eco de las palabras que utiliza Rajoy para impulsar y justificar el cambio de la normativa del mercado de trabajo.

A partir de ello, y según las categorías de análisis construidas ("entidades temáticas") y las sub-categorías ("especificidades del tema”), en el siguiente apartado nos proponemos identificar qué resaltaron Clarín y $L a$ Nación cuando debieron informar a sus lectores sobre la reforma laboral española

\subsection{Tipos de flexibilización que se destacan en la superficie mediática}

Para analizar las referencias a la flexibilización laboral en estas coberturas, nos concentramos en identificar cuánto, cuándo y cómo se destaca este tema y sus diversas tipologías (en salida, en entrada, interna y salarial), durante el período estudiado.

Del análisis de las notas seleccionadas, es posible observar que la flexibilización es nominada en casi la mitad de las noticias que cubren la cuestión de reforma laboral española ( 24 sobre 50) y desagregando el total de 24 noticias, la flexibilización de tipo "salarial" ( 8 sobre 24 ) y "en salida" (7 sobre 24) fueron los sub-temas más mencionados y desarrollados en las coberturas de ambos medios. Desde una panorámica general, como se ve en la figura 5, las referencias a la flexibilización salarial (en color violeta) y en salida (en color rojo), sumadas, constituyen el 62,50 \% del tema de la flexibilización laboral.

FIGURA 5

Evolución de las referencias a los tipos de flexibilización

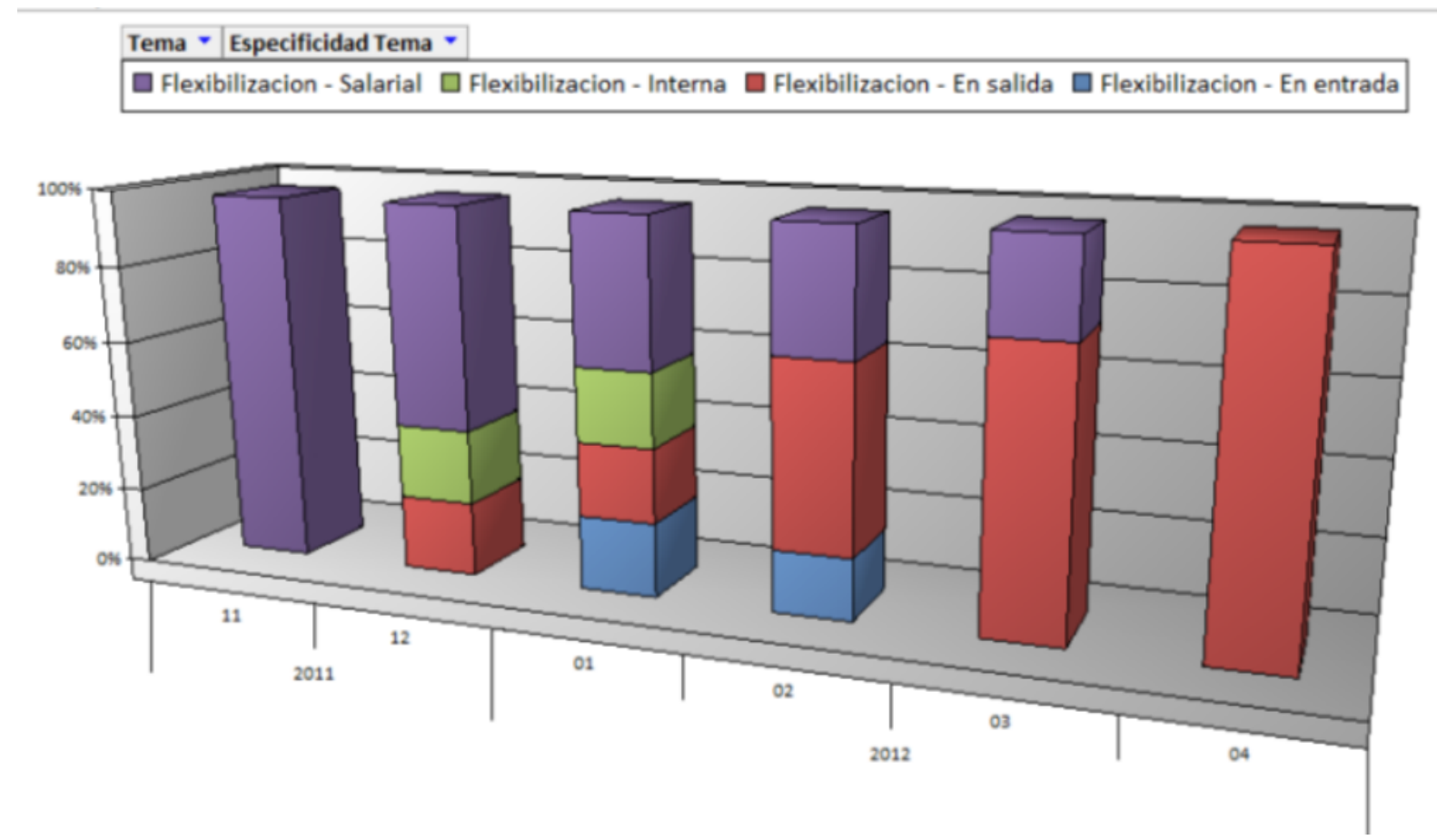

(Fuente: Elaboración propia)

Además, el análisis nos permite distinguir un mayor énfasis en la flexibilización de tipo salarial, en los meses anteriores a la reforma a través de expresiones tales como "salarios congelados", "baja de salarios", y se destaca 
la flexibilización de tipo en salida durante el mes de sanción de la reforma y en los meses posteriores, con expresiones tales como "facilidades para despedir", "despidos más baratos", como es posible ver también en el siguiente ejemplo:

"Un paquete con duras medidas de flexibilización (...) facilita despidos y abre la puerta a una rebaja masiva de sueldos de forma unilateral en las empresas.” (Masiva protesta en España contra la flexibilización laboral, 19/02/2012, La Nación)

Específicamente en el mes de sanción de la reforma (febrero de 2012), como se ilustra en la figura 6, se observa que el sub-tema de flexibilización en salida es el que más fue mencionado (50\%), seguido de salarial (33\%) y luego en entrada (17\%)

FIGURA 6

Referencias mediáticas a la flexibilización en el mes de la reforma

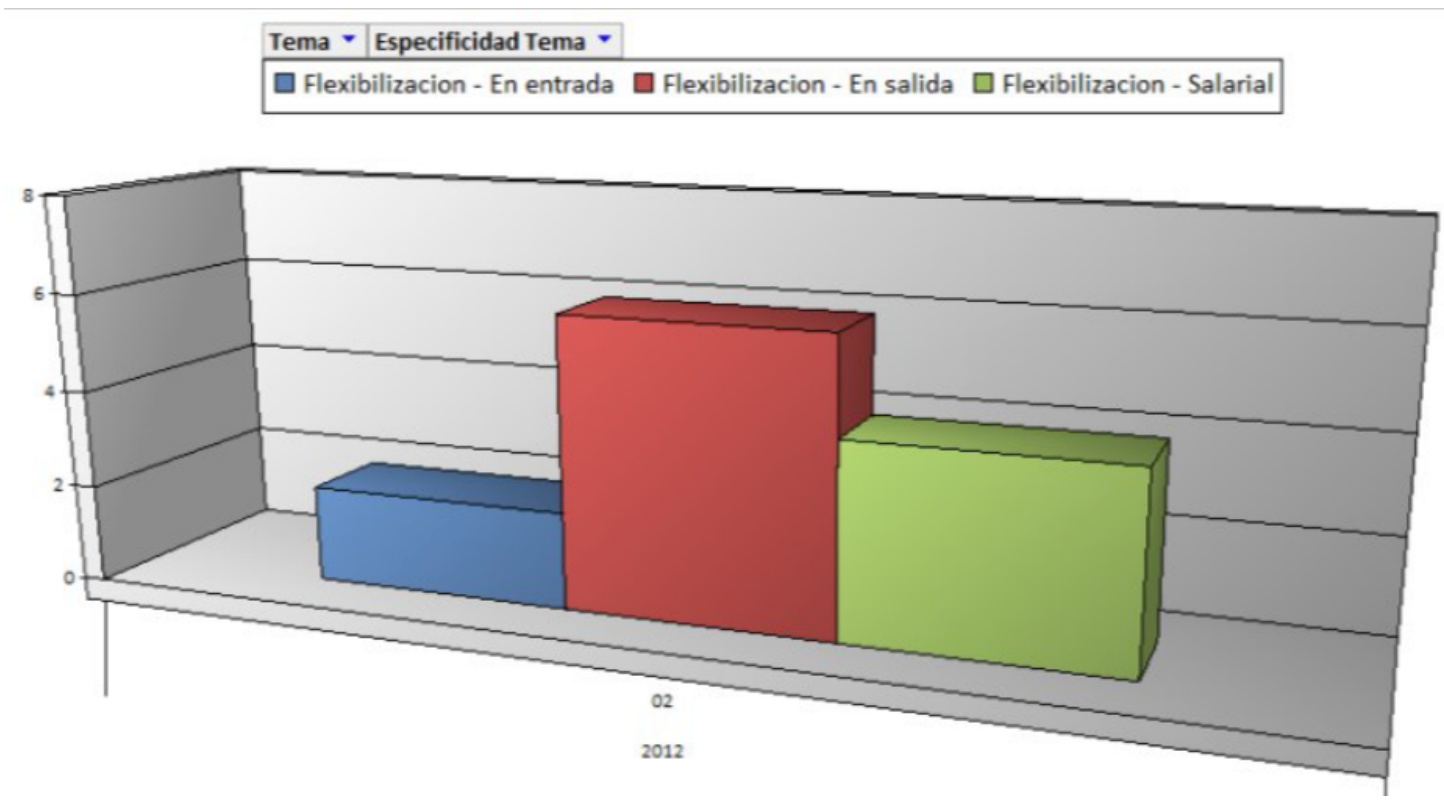

(Fuente: Elaboración propia)

Por lo tanto, es posible afirmar que mientras en los meses previos a la sanción de la reforma el hincapié fue puesto en las disminuciones o el congelamiento de salarios, en el mes de la reforma y aquellos posteriores, el eje de la representación se desplazó hacia la flexibilización en salida, es decir, ya no sólo la reforma suponía rebajas en los salarios y ganar menos por igual tarea, sino más facilidades para las empresas para despedir trabajadores.

En relación con cómo se van sentando las bases ideológicas para construir consensos sobre ciertas temáticas sociales delicadas, si bien la reforma laboral española suponía tanto una rebaja en salarios como en las indemnizaciones, fue posible advertir cómo en los meses previos a ser sancionada la reforma, la cuestión salarial era la más enfatizada mientras en el mes de su sanción y en los meses posteriores era la facilidad para despedir, lo que supone no sólo recibir menos indemnización sino además mayor inestabilidad en el empleo. En otras palabras, la mayor desprotección y pérdida de tutela para los trabajadores se destaca cuando la reforma ya es ley. Relacionado con tales cuestiones de inestabilidad e inseguridad en el empleo, se analiza, en el siguiente apartado, la segunda categoría analítica propuesta: la precarización laboral y los modos en los que fue representada. 


\subsection{Las referencias mediáticas a la precarización laboral}

Como se mencionó previamente, la categoría de precarización fue dividida, en tres sub-categorías que denominamos: "contractual”, "de derechos" y "global”. Nos concentramos, en primer lugar, en conocer qué tipos de precarización se destacaron en los medios argentinos, durante el período analizado.

Lo primero que pudimos observar es que del total de las 50 noticias seleccionadas, sólo 12 mencionaron, específicamente, la noción de la precarización en la cobertura de la reforma laboral española. De estas 12 noticias, son mayormente mencionados las sub-categorías "contractual" ( 5 sobre 12 ), seguida de aquella denominada "de derechos" (4 sobre 12):

\section{FIGURA 7}

Evolución de las referencias mediáticas a la precarización

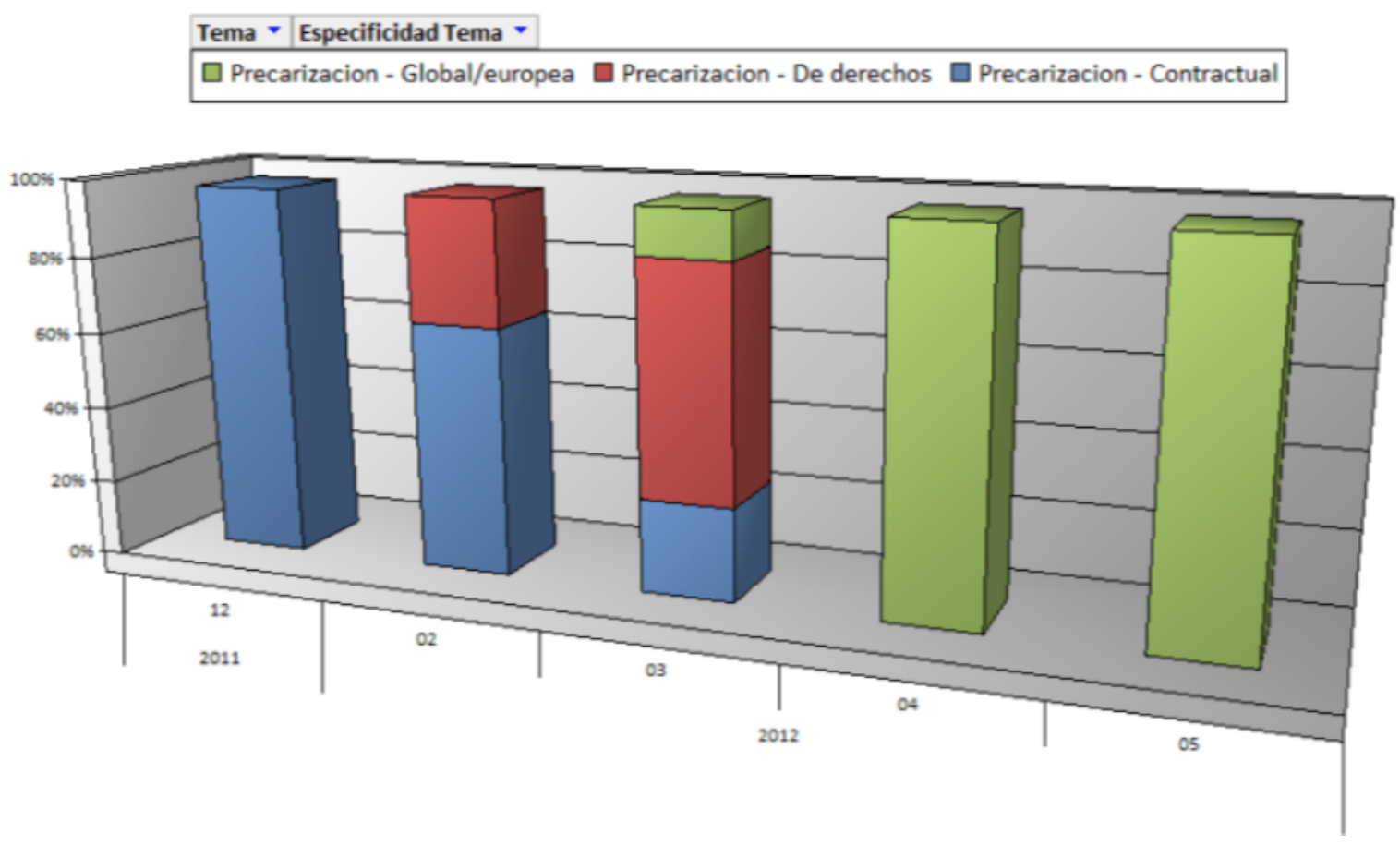

(Fuente: Elaboración propia)

Como puede observarse en este gráfico, entre los meses de diciembre de 2011 y febrero de 2012, es decir, antes y durante el mes de implementación de la reforma, se hizo más bien hincapié en la sub-categoría "contractual", es decir, en las modificaciones de cláusulas de los convenios colectivos de trabajo y las cláusulas de empleos temporales tales como la propuesta de empleos "mini", implementados en Alemania. Aquí se puede ver un ejemplo de ello:

"Los 'miniempleos', la solución de la UE para una España en crisis.

Las empresas españolas los avalan, pero los sindicatos se resisten; en Alemania, 7 millones de personas tienen ese tipo de trabajo” (Los 'miniempleos', la solución de la UE para una España en crisis, 19/01/2012, La Nación).

En cambio, durante los meses de marzo de 2012 y aquellos posteriores, se destaca la precarización de derechos, es decir, nos referimos a que los diarios hicieron referencia, específicamente, a la quita de derechos laborales que comportaba esta reforma, con expresiones tales como "un retroceso de 60 años" (La huelga general en España registra un seguimiento desigual, 29/03/2012, La Nación).

A partir de marzo de 2012, sólo La Nación hace referencia a la sub-categoría de precarización "global/ europea" (3 sobre 12), poniendo en serie discursiva otros casos de ajustes y recortes a nivel europeo como 
Italia y Grecia, a través del uso de recursos visuales y escritos como fotos, destacados y epígrafes, tal como se muestra en la siguiente fotografía tomada de Reuters y publicada en la sección El Mundo, cuyo epígrafe menciona "Los manifestantes también recordaron las recientes medidas de ajuste en Grecia" (Masiva protesta en España contra la flexibilización laboral, 19/02/2012, La Nación).

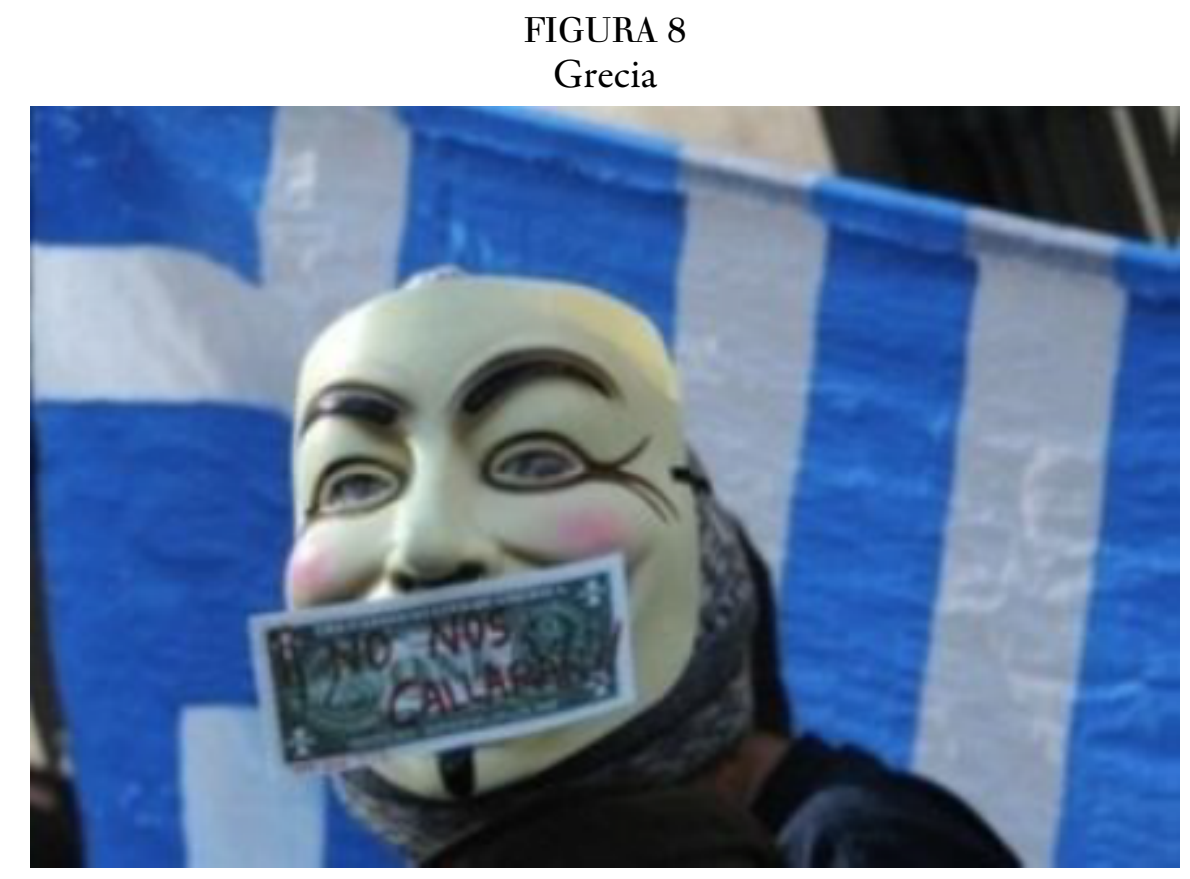

(Masiva protesta en España contra la flexibilización laboral, 19/02/2012, La Nación).

En resumen, es posible afirmar que en los pocos casos en los que se hace referencia a la precarización (12 sobre 50), las coberturas mediáticas privilegian aquella "contractual” (antes y durante la reforma) y sólo después de la sanción de la reforma se destaca explícitamente la quita de derechos y la precarización extendida a otros casos europeos, en el contexto de ajuste y recortes de la zona euro, post crisis del 2008.

\subsection{Los actores privilegiados en las coberturas}

En función de este predominio que hasta aquí hemos visto en las coberturas mediáticas de ambos medios argentinos, sobre la referencia a la flexibilización salarial y en salida, unido a la precarización contractual y de derechos, en este apartado nos centramos en identificar cuáles son las voces o los actores privilegiados que seleccionan estos diarios para construir tales noticias. Parafraseando a Gomis (1991), interpretar una noticia también es preguntarse a quién beneficia y a quién perjudica, dado que las fuentes nunca son inocentes al ofrecer determinada información, ni el diario es inocente al incluirlas y decidir publicarlas.

$\mathrm{Al}$ respecto, hemos podido observar de modo general que los organismos internacionales de crédito (Fondo Monetario Internacional/Unión Europea) y los sindicatos fueron los actores privilegiados en las noticias y son bastantes pocas las referencias al sector empresario en la cuestión.

Llama la atención que en el caso de La Nación siendo un diario que interpela, principalmente, a los grupos de poder, empresarios, elites, dada su identificación histórica con los sectores del "arriba social" (Sidicaro, 1993), las fuentes más consultadas y destacadas sean las voces sindicales, luego los organismos internacionales y solo en tercer lugar, y en muy baja proporción, las voces empresariales, como ilustra la siguiente figura: 
FIGURA 9

Actores privilegiados en La Nación



(Fuente: Elaboración propia)

También en Clarín aparece en tercer lugar y en muy baja proporción el sector empresarial, con referencias sólo en el mes de febrero. No obstante, cabe destacar, que se invierte la proporción sobre los organismos internacionales de crédito y los sindicatos, siendo los primeros aquellos más consultados por este medio, como muestra el siguiente gráfico:

FIGURA 10

Actores privilegiados en Clarín

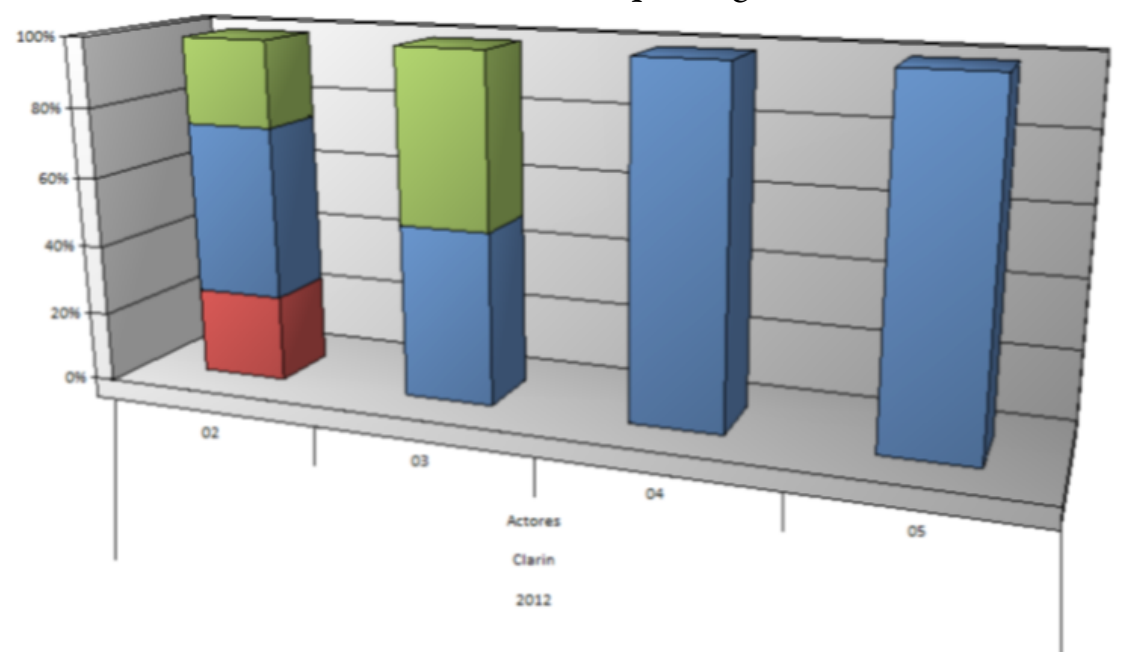

(Fuente: Elaboración propia)

En ambos medios, los organismos internacionales de crédito no sólo son una de las voces privilegiadas en estas coberturas sino que el modo en los cuales se refieren a ellos, otorga una atribución positiva a estos actores. Aquí es posible ver dos ejemplos:

"El Banco de España, la Unión Europea y el Fondo Monetario Internacional, preocupados por un desempleo galopante en España, habían urgido al país a reformar lo antes posible su mercado de trabajo, considerado demasiado rígido.” (El desempleo en España crece sin límites y sigue siendo récord: subió 2,4\%, 2/03/2012, La Nación, -el subrayado es nuestro). 
"La reforma laboral. La medicina amarga recetada por la Unión Europea y el FMI para reducir el déficit fiscal." (Entre la esperanza y la realidad pura, 29/03/12, Clarin, -el subrayado es nuestro).

Desde una perspectiva cultural crítica, que pone énfasis en los sentidos sociales de las construcciones mediáticas, los subrayados que hemos destacado ("preocupados", "medicina amarga") tienden a construir una representación "humanizada" de estos organismos internacionales, presentados como quienes ayudan a los países en dificultad a salir de las crisis e indican el camino -aunque amargo- para hacerlo.

Como se mencionó previamente, otro de los actores privilegiados en las coberturas, sobre todo durante el mes de sanción de la reforma, fueron los sindicatos. Entrevistas a sindicalistas, resaltados de sus argumentos contra la reforma y fotos de agencias de noticias internacionales en las manifestaciones, fueron algunos de los recursos utilizados por los medios argentinos para cubrir la protesta y representar el "descontento" y la "furia" de los trabajadores y de los sindicatos españoles, por la sanción de la reforma. En Clarín -Mundo- se ver un ejemplo escrito que reza "Mientras en la tribunas se sucedían los dirigentes juveniles de los gremios, que leían un manifiesto, vastos sectores del público gritaban ‘'huelga!, ¡huelga!” (Masivas marchas en España contra la reforma laboral impulsada por Rajoy, 20/02/2012, Clarin)

La misma tendencia se ve en este otro ejemplo visual de La Nación -El Mundo- con un epígrafe que destaca "Las dos centrales obreras más grandes, CCOO y UGT, planificaron marchas en 57 ciudades" (Masiva protesta en España contra la flexibilización laboral, 19 de febrero de 2012, La Nación 19/02/2012,. La Nación)

FIGURA 11

"Las dos centrales obreras más grandes, CCOO y UGT, planificaron marchas en 57 ciudades"

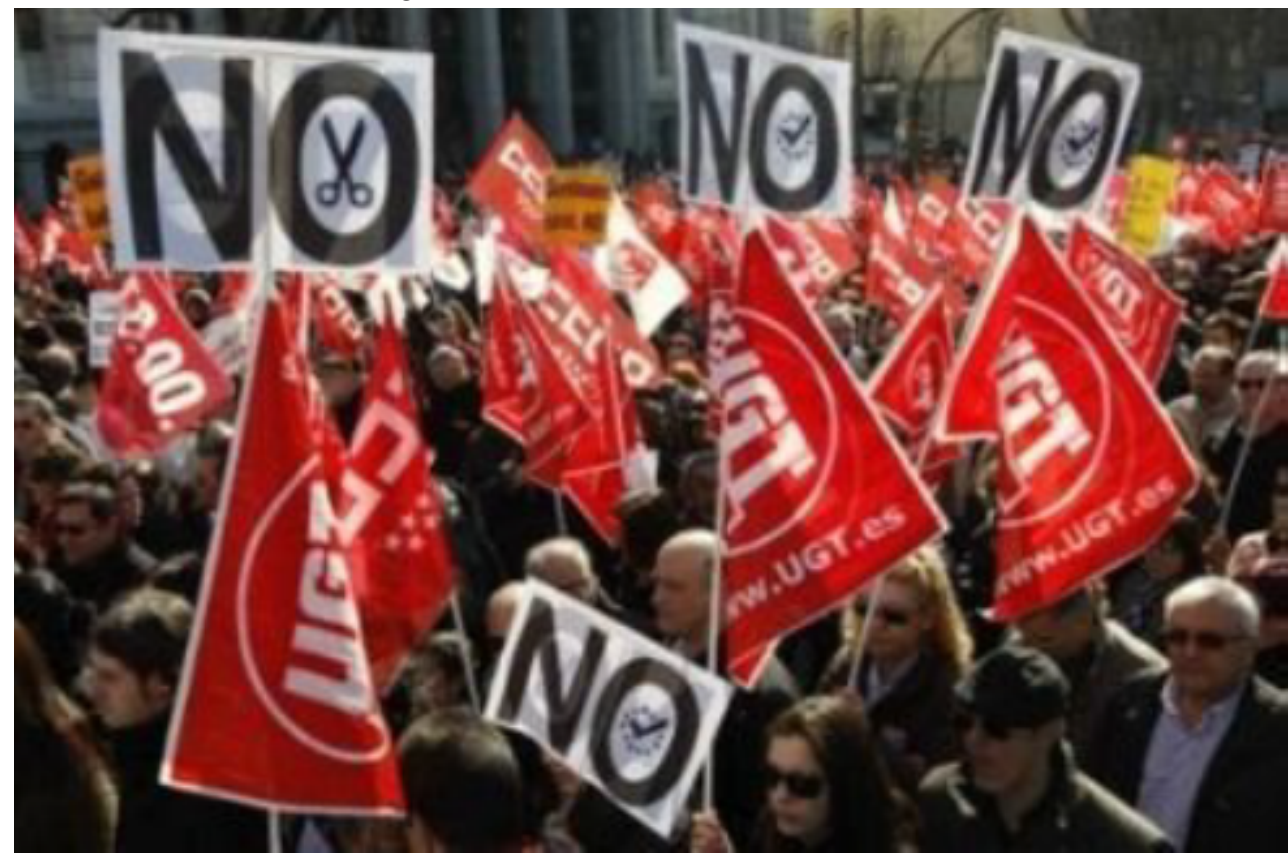

(Masiva protesta en España contra la flexibilización laboral, 19/02/2012, La Nación).

Entre febrero y marzo de 2012, es decir, en el mes de sanción de la reforma y el mes inmediatamente posterior cuando comenzaron a estallar los conflictos, la huelga general adquiere una alta visibilidad en la superficie mediática de los portales digitales argentinos, respecto a la cobertura de otras manifestaciones de protesta como se ve en el siguiente gráfico: 
FIGURA 12

Representación mediática de la huelga general

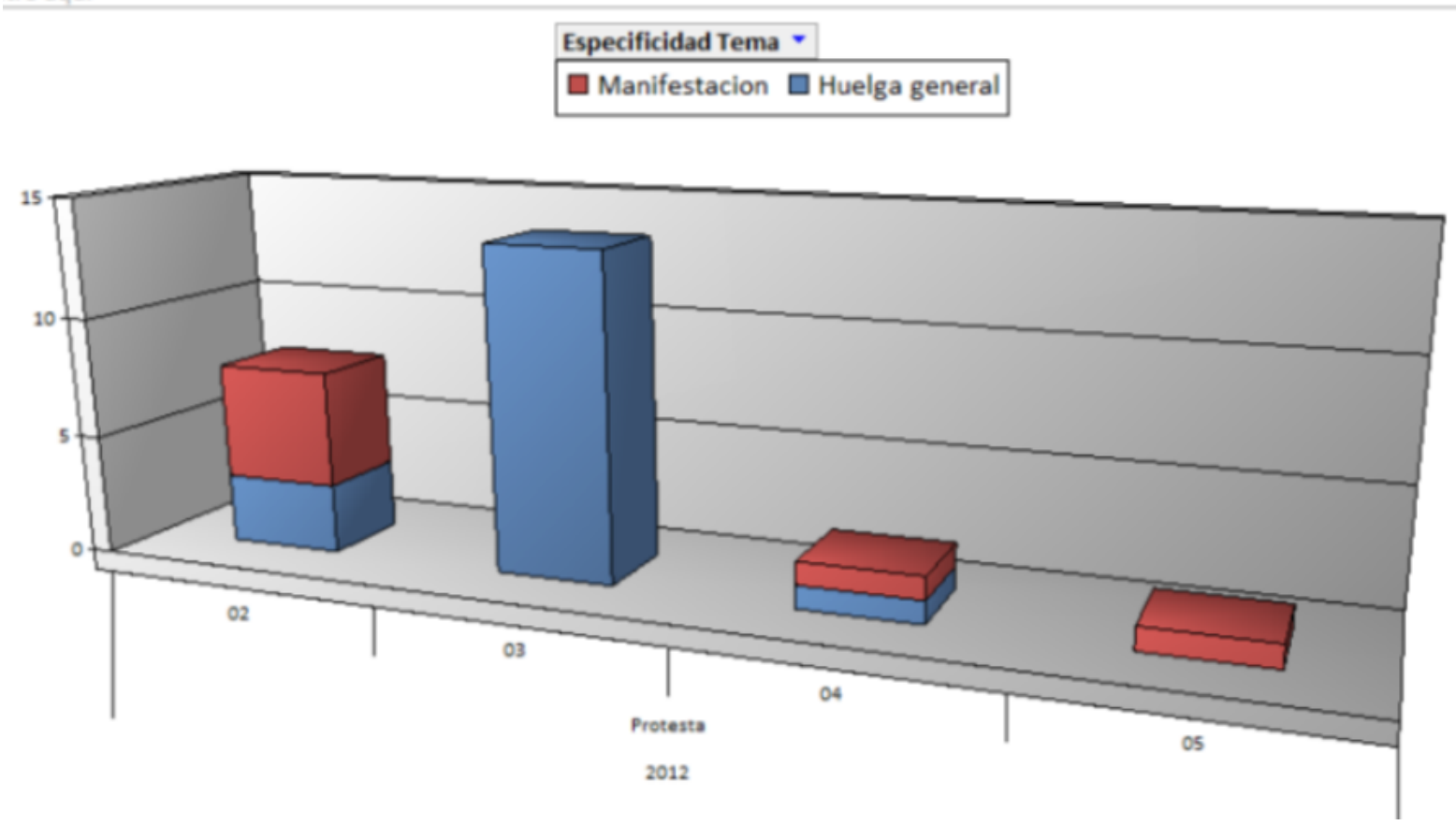

(Fuente: Elaboración propia)

Así, las noticias sobre la huelga general en los diarios argentinos refuerzan el descontento y la resistencia de los trabajadores españoles a la reforma, sin que se advierta una deslegitimación directa a la medida de fuerza, convocada por los principales sindicatos españoles, en las coberturas. ${ }^{8}$

A partir del análisis de los actores y de las voces incluidas en estas noticias, incluyendo aquellas que dieron cuenta de las protestas y las huelgas, es posible afirmar que a diferencia de lo que suele ocurrir cuando los medios argentinos cubren conflictos en Argentina, es decir, que se suele privilegiar la voz empresaria en la cuestión, aquí fueron los organismos internacionales de crédito y los sindicatos españoles los actores más referenciados y destacados en la cobertura mediática.

\section{Conclusiones}

En los modos de construir las noticias sobre la reforma laboral española del 2012, por parte de los diarios argentinos de mayor circulación Clarín y La Nación, hemos visto, en primer lugar, que tanto desde los tags o etiquetas que se utilizan: crisis española, crisis europea o crisis global para enmarcar la noticia sobre la reforma, como desde los adjetivos seleccionados: "descontento", "desamparo", "sombrío", se puede identificar una línea negativa y de dramatización o espectacularización de las noticias. Esto supone que se privilegia el carácter drástico de la situación española y se presenta la reforma laboral como una medida "amarga", en el contexto de una crisis económica global.

En segundo lugar, acerca de la visibilidad otorgada a las nociones claves de flexibilización y de precarización laboral, es importante destacar las diferencias registradas entre aquello reportado en los meses anteriores a la efectiva sanción de la reforma, con aquello que se privilegia en las coberturas mediáticas luego de febrero de 2012.

Un relevamiento panorámico general de la temática de flexibilización laboral nos permitió advertir que las sub-categorías privilegiadas fueron la flexibilización salarial y en salida. Sin embargo, interesa destacar, en particular, los desplazamientos de sentido en las representaciones, según los diversos períodos de análisis. 
En efecto, mientras en los meses previos a la reforma, el hincapié de los diarios argentinos fue puesto en las disminuciones o en el congelamiento de salarios (flexibilización salarial), en el mes de la reforma y los meses posteriores, el eje de la representación se corrió hacia la flexibilización en salida, es decir, las mayores facilidades otorgadas a las empresas para despedir trabajadores, según las modificaciones que introducía la reforma y que se añadían a la baja de salarios, mencionada en los meses previos. Si bien ambos casos suponían peores condiciones laborales, la inestabilidad y pérdida de protecciones para los trabajadores se destaca mayormente cuando la reforma ya es ley.

En función de estas desprotecciones, respecto de la temática de precarización, si bien su mención no adquiere tanta visibilidad como aquella de flexibilización, en los pocos casos en los que se hace referencia a esta noción, las coberturas de ambos diarios privilegian la precarización contractual y de derechos. También en este caso, fue posible advertir que mientras, en los meses previos y durante la sanción de la reforma, se mencionan como modificaciones la introducción de nuevas cláusulas en los contratos colectivos nacionales, es sólo después de su sanción que se destaca explícitamente la quita de derechos laborales que supone para los trabajadores españoles, respecto de las legislaciones laborales anteriores.

En este punto, interesa retomar las implicancias y el rol de los medios de comunicación masiva a la hora de instalar una determinada temática y sus modos de ponerla a circular en la esfera pública. Como se ha visto en trabajos previos (Coscia, 2008) la representación mediática de cuestiones socialmente relevantes como reformas jubilatorias o laborales, en contextos de avance neoliberal, se suelen poner en serie con nociones tales como descrédito estatal, necesidad de "libre competencia", "esfuerzo de los trabajadores", para ir forjando en el debate público las bases ideológicas sobre los modos de pensar y concebir los cambios en las condiciones salariales, los derechos laborales, los sindicatos, en momentos de crisis económica y social.

En línea con estos modos de co-construir ciertos consensos sociales (Gramsci, 1974), respecto de los actores y las fuentes privilegiadas en la cobertura de la reforma española, no llama la atención que una de las voces principales que seleccionaron los medios argentinos fueron los organismos internacionales de crédito (FMI/UE), quienes van imponiendo a los países recetas y ajustes para "salir de la crisis". En las coberturas sobre la reforma laboral española se advierte, además, una representación "humanizada” de estos organismos internacionales, tal como ocurría con las medidas del llamado Consenso de Washington en los años' 90.

Retomando a Hall (1981), se trata de analizar las batallas culturales y las dinámicas de poder que se dan en los procesos de construcción de sentido, en cada coyuntura y con sus especificidades. Se espera que este estudio pueda contribuir a delinear indicios acerca de aquello que se mencionó al inicio sobre una "hegemonía de lo pensable y de lo decible" (Angenot, 2012), es decir, acerca de la legitimación y/o deslegitimación de las protestas, las reformas laborales, las condiciones de trabajo, los sindicatos y los derechos de los trabajadores en las sociedades contemporáneas y en un contexto global de avance neoliberal. El caso de la reforma española, aquí analizado, consideramos que permitirá identificar, en futuros análisis, elementos análogos o disímiles con las construcciones noticiosas de otras reformas laborales recientes en América Latina, como México, Brasil o incluso aquella que se propone actualmente para Argentina y que desde 2017 se impone como uno de los temas de la agenda pública nacional.

\section{REFERENCIAS}

Angenot, M. (2012). El discurso social. Los límites históricos de lo pensable y lo decible. Buenos Aires: Siglo XXI editores. Bernstein, B. (1998). Pedagogía, control simbólico e identidad. Madrid: Morata.

Barthes, R. (1962). Estructura del Suceso. En Ensayos Criticos (pp.225-236), Barcelona: Seix Barral.

Basile, R.(2009) Mito e inganno. La rappresentazione della flesibilità del lavoro nel dibattito pubblico. En G. Altieri. (coord.) Un mercato del lavoro atípico. Storia ed effetti della flessibilità in Italia (pp.155-190), Roma: Ediesse.

Beneyto, P. J. (2012) Sobre la legitimidad del sindicalismo, Derechos y fuentes de financiación en España y la Unión Europea, Documento Fundación $1^{\circ}$ de Mayo. Confederación Sindical de Comisiones Obreras (CCOO), 3-41. 
Bentolila S. y Jansenn M. (2012). La reforma laboral de 2012: Una primera evaluación. Apuntes Laboral Federación de Estudios de Economía Aplicada (FEDEA), Madrid, 14, 2-16. Texto completo en http://documentos.fedea.net/ pubs/ap/2012/al-2012-14.pdfFecha de consulta enero de 2019.

Bourdieu, P. (1998). La esencia del neoliberalismo. Le Monde Diplomatique, n528. Marzo. 3.

Bonofiglio, N. y Fernández, A. L. (2003) Los trabajadores y el trabajo en la crisis. En 6to Congreso Nacional de Estudios del Trabajo (ASET), Buenos Aires,13-16 agosto.

Confederación Sindical de Comisiones Obreras (2012) "Las reformas laborales en España y su repercusión en materia de contratación y empleo. Cincuenta y dos reformas desde la aprobación del Estatuto de los Trabajadores en 1980". Documento Fundación 1 de Mayo, CCCO. Febrero, 3-79.

Coscia, V. (2008) La privatización como salida a la crisis de fines de los 80. Un análisis desde las estrategias mediáticas. Papeles de trabajo de la Universidad Nacional de San Martin, 4, 1-24.

Coscia, V. (2016) Herramientas socio-semióticas para abordar las 'narrativas de la protesta' en medios gráficos masivo. AdVersus, Revista de semiótica dell' Istituto Italo-Argentino di Ricerca Sociale, 31, 118-140.

Coscia, V. (2017) Reformas laborales, sindicatos y conflictividad en los medios masivos: apuntes para una comparación globa., Revista Methaodos, 5 (2), 292-301

De la Garza Toledo, E. (2000a). “La flexibilidad del trabajo en América Latina”. En De la Garza Toledo, E. (coord.) Tratado Latinoamericano de Sociología del Trabajo (pp. 151-178) México: Fondo de Cultura Económica.

De la Garza Toledo, E. (2000b). Las teorías sobre la reestructuración productiva y América Latina. En De la Garza Toledo, E. (coord.) Tratado Latinoamericano de Sociología del Trabajo (pp. 716-734), México: Fondo de Cultura Económica.

De Vito, C. (2018). Passato precario. Flessibilità e precarietà del lavoro come strumenti concettuali per lo studio storico delle interazioni tra rapporti di lavoro. En Bonazza, Giulia \& Ongaro, Giulio (Comp.). Libertá e coercizione: il lavoro in una prospettiva di lungo periodo (pp. 123-162). Palermo: Sislav\& New Digital Frontiers.

Ford, A. (1994) Navegaciones. Comunicación, cultura y crisis. Buenos Aires: Amorrortu.

Gallino, L. (2014). Vite rinviate. Lo scandalo del lavoro precario. Roma: Ed. Laterza.

Gomis, L. (1991) Teoria del periodismo. Cómo se forma el presente, Barcelona: Paidós Ibérica.

Gramsci, A. (1974). Literatura y Cultura Popular, Tomo I. Buenos Aires: Cuadernos de Cultura Revolucionaria [Gl iintellettuali e l'organizzazione della cultura, 1949].

Hall, S., (1981) La cultura, los medios de comunicación y el 'efecto ideológico. En Curran, J. et. al. (comp) Sociedady comunicación de masas (pp. 221-254). México: Fondo de Cultura Económica.

Hall, S. (2010) El trabajo de la representación. En: Hall, S., Restrepo, E., Walsh, C. \& Vich, V. M. Sin garantías. Trayectorias y problemáticas en estudios culturales (pp. 447-482). Quito: Corporación Editora Nacional, CEN; Universidad Andina Simón Bolívar, Sede Ecuador; Pontificia Universidad Javeriana. Instituto de Estudios Sociales y Culturales Pensar; Instituto de Estudios Peruanos, IEP.

Imbert, G. (2002). Azar, conflicto, accidente, catástrofe. Figuras arcaicas en el discurso posmoderno. Trama y Forma, No 12, pp. 19-30. Disponible en http://www.tramayfondo.com/revista/libros/47/imbert.pdf

Lindenboim, J.; Serino, L; González, M. (2000) La precariedad como forma de exclusión, en Cuaderno del CEPED No 4. Texto completo en http://biblioteca.clacso.edu.ar/gsdl/collect/ar/ar-008/index/assoc/HASH01fb.dir/CU A7.html fecha de consulta enero de 2019

Marshall, A. (1997). Protección del empleo en América Latina: Las reformas de los '90 y sus efectos en el mercado de trabajo. En E. Villanueva (coord.). Empleo y Globalización (pp. 427-458). Bernal: Universidad de Quilmes.

Rodríguez, M. G.(2014). Sociedad, cultura y poder. Reflexiones teóricas y líneas de investigación. San Martín: Universidad Nacional de General San Martín.

Russo, R. (2013). "Modelli e strumenti di Business Intelligence e Data Mining Strategie per l'integrazione e rappresentazione dei dati ed analisi a supporto dei processi decisionali e di business aziendali", Documento de trabajo para curso Banca d'Italia, Escuela de Formación Reiss Romoli, noviembre, Roma (inédito). 
Sidicaro, R. (1993) La política mirada desde arriba. Las ideas del Diario La Nación 1909-1989. Buenos Aires: Sudamericana.

Sontag, S. (2004) Ante el dolor de los demás. Madrid: Santillana Ediciones.

\section{ReFERENCIAS DiARIOS CLARÍN y LA NACióN}

España aplica más ajustes y congela el salario mínimo. (29 de diciembre de 2011), Clarín. Recuperado de https://ww w.clarin.com/mundo/espana-ajustes-congela-salario-minimo_0_BkZSxWt3wQl.html

El desempleo en España crece sin límites y sigue siendo récord: subió 2,4\%. (2 de marzo de 2012), La Nación -El Mundo-. Recuperado de https://www.lanacion.com.ar/el-mundo/el-desempleo-en-espana-crece-sin-limites-ysigue-siendo-record-subio-24-nid1453169

Entre la esperanza y la realidad pura. (29 de marzo de 2012), Clarin. Recuperado de https://www.clarin.com/.../esp eranza-realidad-pura_0_ryHbZABnwXg.html

La huelga general en España registra un seguimiento desigual. (29 de marzo de 2012). La Nación -El MundoRecuperado de: https://www.lanacion.com.ar/el-mundo/comenzo-la-huelga-general-en-espana-masivo-acatam iento-nid 1460588

Los 'miniempleos', la solución de la UE para una España en crisis. (19 de enero de 2012), La Nación. Recuperado de https://www.lanacion.com.ar/el-mundo/mini-trabajos-nid1439610

Masiva protesta en España contra la flexibilización laboral. (19 de febrero de 2012). La Nación -El MundoRecuperado de https://www.lanacion.com.ar/el-mundo/masiva-protesta-en-espana-contra-la-flexibilizacion-la boral-nid 1450060

Rajoy advierte que la economía y la desocupación española empeorarán, 16 de febrero de 2012, Clarín. Recuperado de: https://www.clarin.com/mundo/rajoy-economia-desocupacion-espanola-empeoraran_0_H15XqSwnP7g. html

Masivas marchas en España contra la reforma laboral impulsada por Rajoy. (20 de febrero de 2012). Clarín. Recuperado de https://www.clarin.com/mundo/masivas-espana-reforma-impulsada-rajoy_0_BJCEamvnP7g.html

\section{Notas}

1 Respecto de la nominación flexibilización/flexibilidad, debemos precisar que, en términos gramaticales, el sufijo "ción" proviene del latin "tion" y se une al verbo para expresar una acción yun efecto de dicha acción, mientras el sufijo "dad", proviene del latin "tas, atis" e indica una cualidad o una relación con. Consideramos que la acción o efecto de flexibilizar y de precarizar enmarca la temática en un proceso social, al tratarse de acciones que afectan directamente a los trabajadores y que reconfiguran las relaciones de fuerza. También desde el campo de los estudios laborales, algunos autores han preferido hablar de flexibilización justamente debido a esta idea de proceso, de acción y devenir de normas, prácticas y relaciones flexibles (Marshall, 1997).

2 Para ampliar sobre las especificidades del enfoque construccionista de la representación y la producción de sentidos sociales en cada coyuntura histórica, las diferencias y coincidencias con las nociones de discurso y de poder en Foucault y los puntos de contacto con el concepto de mito de Barthes, en Hall (2010).

3 Para profundizar en las características de esta reforma y sus efectos sobre los trabajadores españoles consultar Bentolila y Jansen (2012) y el informe de la Confederación Sindical de Comisiones Obreras-CCOO- (2012).

4 Sobre el abordaje metodológico en relación con los elementos de construcción de las noticias y las narrativas sobre conflicto laboral y mundo del trabajo, ver Coscia, 2016.

5 Dado que se trata de un tema internacional o del exterior para los diarios argentinos, en base a criterios de noticiabilidad, propios de las rutinas periodísticas, la cantidad de noticias dedicadas a la temática va a ser mucho más acotada que aquella que realizan los principales diarios españoles sobre el mismo tema. De todas formas, no se desconoce la potencialidad de las herramientas del datamodelling y del datawarehouse para la modelización y el análisis de grandes masas de datos.

6 El conjunto de estos pequeños depósitos para el análisis de datos (datamart) pueden conformar, en grandes cantidades, un data warehouse. El data-warehouse es un gran modelo de repositorio de datos, con diversas fact tables relacionadas entre sí, que a su vez se relacionan con distintas dimensiones de análisis, tiene una alta capacidad de almacenamiento de datos, y en general se utiliza en el ámbito comercial de las empresas privadas en el sector del Business Intelligence 
VANesa Coscia, et al. La reforma laboral española SEgún los diarios argentinos

(BI).Se trata de un instrumento cualitativo utilizado, estratégicamente, para obtener la máxima ventaja del patrimonio de datos disponibles, desarrollar tendencias y previsiones comerciales, anticipar y responder eficazmente a la necesidad de los clientes, reclutar nuevos y mejorar los niveles de satisfacción de los antiguos. (Russo, 2013).

7 Esto se diferencia de aquello que los principales diarios españoles, El País y El Mundo, resaltaron cuando cubrieron su propia reforma laboral, otorgando un carácter más literal e informativo al marco o etiquetado de tales noticias. Para ampliar este análisis ver Coscia, 2017.

8 Aquí también puede señalarse otra diferencia entre las coberturas de diarios argentinos y españoles. Tanto El País como El Mundo en sus referencias a la huelga general, en el marco de las noticias publicadas sobre reforma laboral en 2012 , enfatizan, a través de distintos mecanismos discursivos, sentidos tales como que la huelga es "obsoleta", "fuera de moda" o “inadecuada”. Ver Coscia, 2017.

\section{BY-NC-SA}

